\title{
Deterministic and Probabilistic Earthquake Scenarios for the Seismic Risk Analysis of URM Buildings
}

\author{
Avila-Haro J. A. ${ }^{1, a}$, González-Drigo J.R. ${ }^{1, b}$, Vargas Y. F. ${ }^{2, c}$, Pujades L. G. ${ }^{2, d}$ \\ and Barbat A. H. ${ }^{1, e}$
}

${ }^{1}$ RMEE Technical University of Catalonia, Barcelona, Spain

${ }^{2}$ ETCG Technical University of Catalonia, Barcelona, Spain

ajorge.avila-haro@upc.edu, bjose.ramon.gonzalez@upc.edu, cyeudy.felipe.vargas@upc.edu,

dlluis.pujades@upc.edu, ealex.barbat@upc.edu

Keywords: unreinforced masonry, deterministic spectra, probabilistic spectra, risk analysis.

\begin{abstract}
Barcelona, as well as a large number of cities in the Mediterranean basin, has a housing stock composed of a large number of unreinforced brick masonry buildings. Motivated by different factors, the enlargement of the city (Eixample in Catalan) was held from the second half of the 19th century and the beginning of the 20th, a period in which a large number of buildings of this type were built, many of which are still used as dwellings.

Although the buildings were built individually, some of them are linked to adjacent buildings by the side walls. This feature leads to the analysis of the buildings as isolated structures and also as an aggregate.

Barcelona is located in a seismic region of low to moderate hazard, with macroseismic intensity between the grades VI and VII of the European macroseismic scale EMS'98. Based on the deterministic and probabilistic response spectra for the different types of soils present in Barcelona obtained in the work of Irizarry (2004), the seismic risk of four individual buildings and an aggregate is evaluated. The buildings are modeled and analyzed using the TREMURI program and MATLAB routines under the guidance of RISK-UE project.
\end{abstract}

\section{Introduction}

The modern cities of the Mediterranean basin accumulate a large stock of infrastructures, resulting in a concentration of important socioeconomic value. The construction period, typology, materials and code levels in an important number of buildings of this stock, lead us to evaluate the seismic hazard and vulnerability of some of them.

In the case of Barcelona city, originally founded by Romans between the 15 to 10 years B.C., the enlargement of the city (example in Catalan) took place during the second half of the 19th century and the beginning of the 20th century. During this period of expansion, most of the buildings were constructed with unreinforced brick masonry and without any seismic consideration. Nowadays, many of those ancient buildings are still used as dwellings, largely surpassing their initially supposed service life.

Sometimes, the constructive habits of the time allowed the construction of the buildings not only as isolated structures but also as buildings assembled to each other as aggregates, constituting the so called blocks.

Following the guidance of the RISK-UE project [1], the aim of this work is to assess the seismic risk and vulnerability of the isolated and aggregated buildings. The structural analysis is performed with the TREMURI [2] program and some MATLAB (Matlab, v.2009b, The Mathworks), routines that allow us to obtain the different results concerning fragility and damage.

Based on the work and results obtained by Irizarry (2004), we have been able to analyze the buildings for a deterministic and a probabilistic earthquake scenario for the corresponding type of soil where these buildings are located. 


\section{The buildings}

The studied buildings correspond to a block section located in Muntaner Street in the city of Barcelona, Spain. The four isolated buildings correspond to the numbers 153, 155, 157 and 159, and the aggregate corresponds to the buildings with the number 153 and 155, whom happen to be identical (Fig. 1).

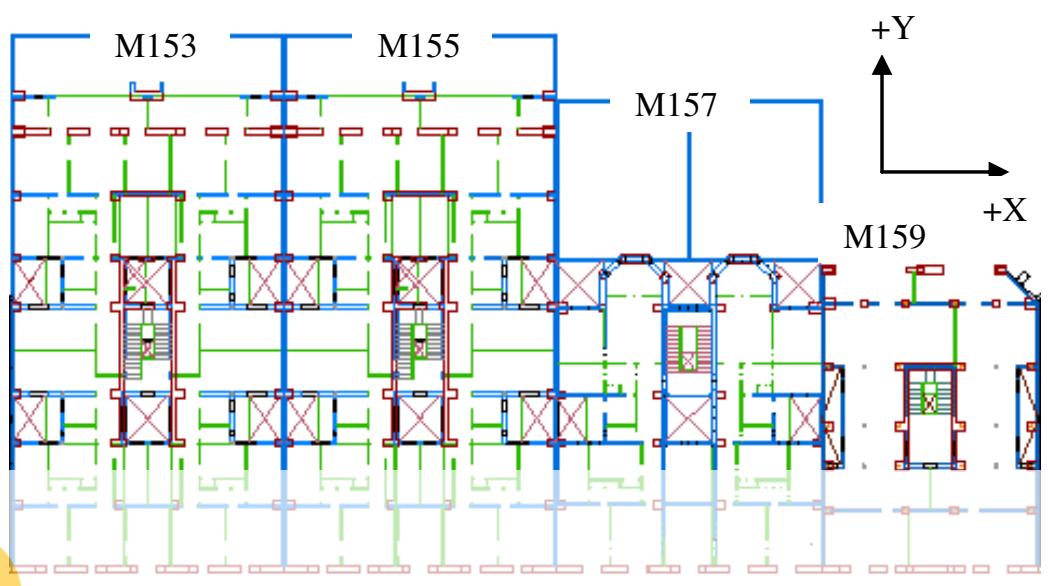

Fig. 1 Floor plan of the analyzed buildings

The buildings are quite representative of the typology of buildings existent in the Eixample district, presenting bearing walls as main resistant elements and, in some cases in the base levels, masonry or cast iron columns. The evaluated structures have 7 levels.

The façade walls preser levels. In the case of the sill the consequent levels.
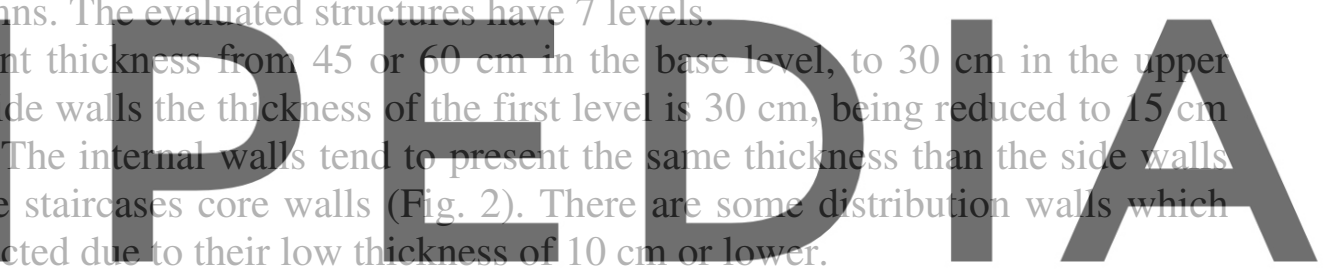

Register for free at https//www.scipedia.com to download the version without the watermark

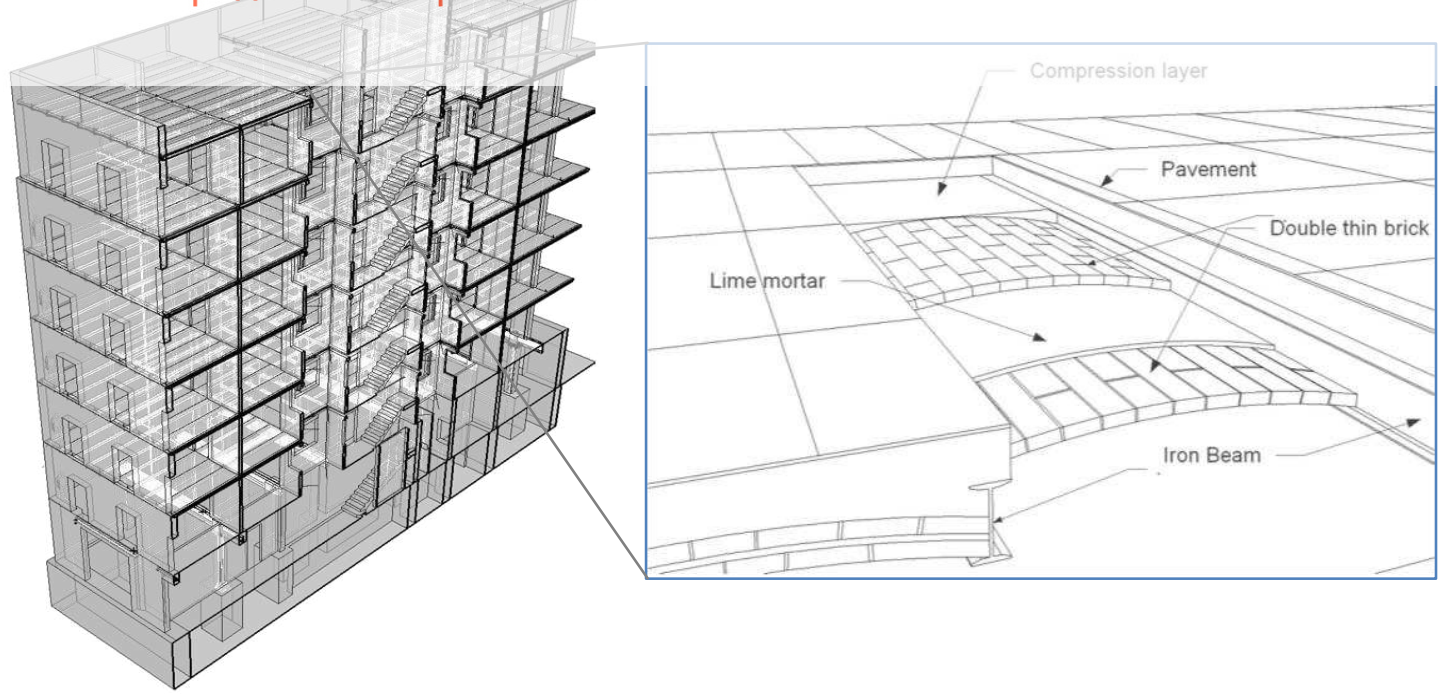

Fig. 2 Section cut of one of M153 building and its floor system

We can observe in the different type of walls the presence of big openings that work as doorways or windows, which loads are discharged via iron or wood lintels or via arches. In the case of the floors, for this particular construction period it is usual to find one-way timber floors, wood beams and brick vaults or, like in our buildings, iron beams and brick vaults (Fig. 2). The size and separation of the beams depends on the total distance that they cover, usually having separations between $60 \mathrm{~cm}$ and $120 \mathrm{~cm}$. 


\section{The demand}

Barcelona is located in a low-to-moderate seismic region. The data related to the demand used in this work includes the 5 percent-damped demand spectra proposed in the RISK-UE project, originally deduced by the University of Genoa [3]. The different soil types present in the city and the main features for the acceleration response spectra for the deterministic and probabilistic earthquake scenarios were obtained from the previous studies performed by Cid (1998) and Irizarry (2004). The analyzed buildings are located in the Eixample neiborghood, wich is placed in the soil zone II.

\begin{tabular}{|c|c|c|c|c|c|c|c|c|}
\hline \multirow[b]{2}{*}{ Soil Zone } & \multicolumn{7}{|c|}{ Parameters } & \multirow[b]{2}{*}{ Scenario } \\
\hline & $p g a[\mathrm{~g}]$ & $\mathrm{T}_{\mathrm{B}}$ & $\mathrm{T}_{\mathrm{C}}$ & $\mathrm{B}_{\mathrm{C}}$ & $\mathrm{d}$ & $\mathrm{T}_{\mathrm{D}}$ & $\mathrm{B}_{\mathrm{D}}$ & \\
\hline & 0.194 & 0.10 & 0.22 & 2.45 & 1.43 & 2.20 & 0.09 & Deterministic \\
\hline & 0.141 & 0.10 & 0.23 & 2.50 & 1.28 & 2.21 & 0.14 & Probabilistic \\
\hline
\end{tabular}

Table 1. Parameters for the deterministic and probabilistic scenarios $\lceil 4\rceil$

\section{The capacity and fragility}

The procedure followed in order to assess the capacity and fragility is based on the capacity spectrum method, which provides a graphical representation of the structure's force-displacement capacity curve and compares it to the response spectra representations of the seismic demand $[5,6]$.

The RISK-UE guidelines [1] define an undamaged state (NO) and four damage states, $d_{s i}$, which : Slight (SL), Moderate (MO), Severe (SE) and Collapse (CO). For the purpose of this work the Chosen parameter in order to define the scismic action will be the spectrar displacement, $S_{d}$, and the damage states are defined from the parameters of the bilinear representation of the capacity Spectrum, as follows: $\overline{\mathrm{ds}}_{1}=0.7 \mathrm{D}_{\mathrm{y}} ; \overline{\mathrm{ds}}_{\mathrm{z}}-\mathrm{D}_{\mathrm{y}} ; \overline{\mathrm{ds}}_{3}=\mathrm{D}_{\mathrm{y}}+0.25\left(\mathrm{D}_{\mathrm{u}}-\mathrm{D}_{\mathrm{y}}\right)$; and $\overline{\mathrm{ds}}_{4}=\mathrm{D}_{\mathrm{u}}$, where,

is the displacement at the yielding point and $\mathrm{D}_{\mathrm{u}}$ is the displacement at the ultimate point.

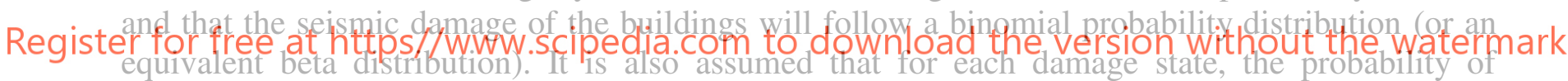
reaching or exceeding that particular damage state will be $50 \%$.
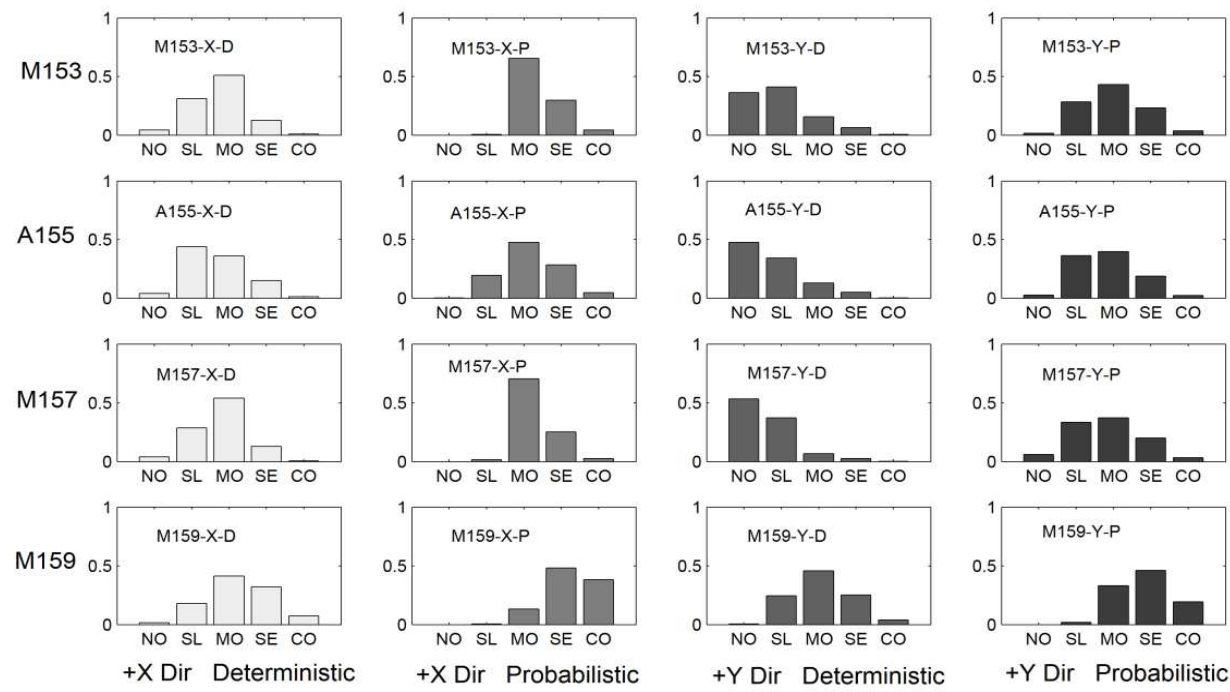

Fig. 3 Damage states distributions for each analyzed building, direction and scenario

Following the mentioned methodology and assumptions we can observe in Fig. 3 the damage states distributions for each building it its two directions, $+\mathrm{X}$ and $+\mathrm{Y}$, and for both seismic scenarios, deterministic and probabilistic. 


\section{Discussion and Conclusions}

For both directions, the probabilistic scenario presents higher damage values and worst performance than the deterministic scenario, in consistency with the corresponding pga values. For both scenarios, we can observe a better performance in the $+Y$ direction rather than in the $+X$ direction (short direction).

In the case of the aggregate buildings, and comparing the results to those obtained for the isolated building M153, we can observe a significant improvement especially in the $+\mathrm{Y}$ direction, suggesting a positive effect for this construction habit.

For the rectangular plan buildings (M153 and M157) we can notice that the damage state probabilities, in the $+X$ direction, are centered between the slight and moderate states for the deterministic scenario, and between moderate and sever for the probabilistic scenario, meanwhile for $+Y$ direction the damage is centered between the no damage and the slight states, for the deterministic scenario, and between slight and moderate for the probabilistic scenario. Buildings with a more squared floor plan (M159) show closer values of fragility.

The results indicates that the expected damage associated to these unreinforced masonry buildings of Barcelona is predominantly moderate

\section{Acknowledgements}

This work was partially funded by the Spanish Science and Innovation Ministry, by the European Commission with FEDER funding through the investigation projects: CGL2008-00869/BTE, SEDURECCONSOLIDER: CSD2006-00060, INTERREG: POCTEFA 2007-2013/73/08 and
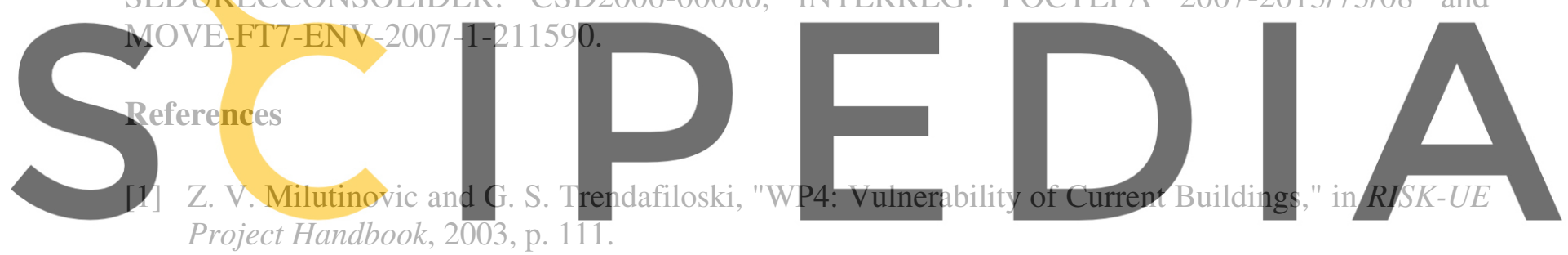

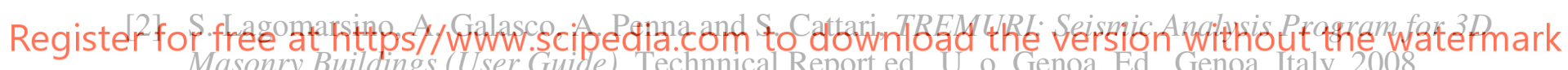
Masonry Buildings (User Guide), Technnical Report ed., U. o. Genoa, Ed., Genoa, Italy, 2008.

S. Lagomarsino, A. Galasco and A. Penna, "Pushover and dynamic analysis of URM buildings by means of a non-linear macro-element model," in International Conference on Earthquake Loss Estimation and Risk Reduction, Bucharest, 2002.

[4] J. Irizarry, X. Goula and T. Susagna, "Evaluación de la peligrosidad sísmica de la ciudad de Barcelona en términos de aceleración espectral," in $2 o$ Congreso Nacional de Ingeniería Sísmica, Málaga, Spain, 2003.

[5] ATC-40, "Seismic Evaluation and Retrofit of Concrete Buildings," Seismic Safety Comission, Redwood City, CA, 1996.

[6] P. Fajfar and P. Gaspersic, "The N2 Method for the seismic damage analysis of RC buildings," Earthquake Engineering \& Structural Dynamics, vol. 25, no. 1, pp. 31-46, 1998.

[7] FEMA/NIBS, HAZUS Technical Manual SR2, Vols. 1, 2, 3, Federal-Emergency-ManagementAgency and National-Institute-of-Building-Sciences, Eds., Washington, 2002.

[8] J. Cid, "Zonación Sísmica de la ciudad de Barcelona basada en métodos de simulación numérica de efectos locales," Universitat Politècnica de Catalunya, Barcelona, Spain, 1998.

[9] J. Irizarry, "An Advanced Approach to Seismic Risk Assessment. Application to the Cultural Heritage and the Urban System Barcelona," Universidad Politécnica de Cataluña, Barcelona, Spain, 2004.

[10] A. J. Kappos, "Seismic damage indices for RC buildings: evaluation of concepts and procedures," Progress in Structural Engineering and Materials, vol. 1, no. 1, pp. 78-87, 1997. 
Advances in Fracture and Damage Mechanics XI

10.4028/www.scientific.net/KEM.525-526

Deterministic and Probabilistic Earthquake Scenarios for the Seismic Risk Analysis of URM Buildings 10.4028/www.scientific.net/KEM.525-526.537
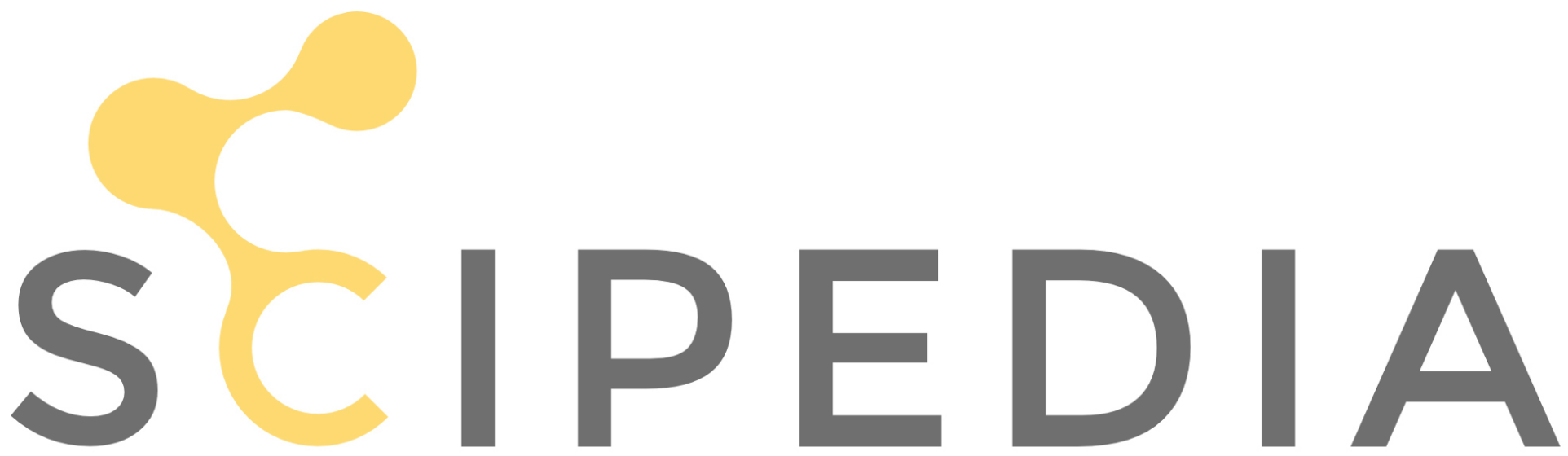

Register for free at https//www.scipedia.com to download the version without the watermark 